\title{
Sobrevivência e viabilidade de escleródios de Sclerotium cepivorum no solo
}

\author{
Leandro Luiz Marcuzzo ${ }^{1}$, Josué Schmoeller ${ }^{1}$
}

${ }^{1}$ Instituto Federal Catarinense - IFC/Campus Rio do Sul, CP 441, CEP 89.163-356, Rio do Sul, SC.

Autor para correspondência: Leandro Luiz Marcuzzo (leandro.marcuzzo@ifc.edu.br)

Data de chegada: 03/08/2016. Aceito para publicação em: 14/02/2017.

$10.1590 / 0100-5405 / 167306$

\section{RESUMO}

Marcuzzo, L.L.; Schmoeller, J. Sobrevivência e viabilidade de escleródios de Sclerotium cepivorum no solo. Summa Phytopathologica, v.43, n.2, p.161-163, 2017.

Em experimento de campo quantificou-se a sobrevivência e a viabilidade de escleródios de Sclerotium cepivorum no solo. Cem escleródios multiplicados em meio de cultura BDA foram colocados em saquinhos feito de tecido. Em armação de madeira contendo solo, colocaram-se 12 repetições respectivamente na superfície e enterrados a 10 centímetros. Mensalmente os saquinhos foram retirados de cada posição, lavados em água corrente e submetidos à compressão com agulha histológica para constatar-se os mesmos mantinham-se intactos. Os escleródios intactos foram submetidos à assepsia com álcool $70 \%$ durante um minuto, hipoclorito de sódio $1,25 \%$ por três minutos e em água estéril para lavagem, em seguida depositado em placas contendo meio BDA e acondicionado em câmara de crescimento a $20^{\circ} \mathrm{C}$ sem luz. Durante os dias de incubação realizava-se a contagem dos escleródios germinados, até o sétimo dia. Os escleródios coletados na superfície perderam sua viabilidade após três meses e os enterrados permaneceram viáveis até sétimo mês. Os escleródios de $S$. cepivorum na superfície tendem a perderem sua viabilidade num período de tempo menor que os enterrados

Palavras-chave: estrutura de repouso, longevidade, viabilidade.

\section{ABSTRACT}

Marcuzzo, L.L.; Schmoeller, J. Survival and viability of sclerotia from Sclerotium cepivorum in soil. Summa Phytopathologica, v.43, n.2, p.161$163,2017$.

In a field experiment, the survival and viability of sclerotia from Sclerotium cepivorum in the soil was quantified. One hundred sclerotia were multiplied on PDA culture medium and stored in fabric bags. In a wooden frame containing soil, 12 replicates were placed respectively on the surface and buried at $10 \mathrm{~cm}$ depth. Every month, bags were removed from each position, washed in water and subject to compression with a histological needle to verify whether they were intact. Intact sclerotia were sterilized with $70 \%$ ethanol for one minute,
$1.25 \%$ sodium hypochlorite for three minutes and sterile water for washing; then, they were deposited on plates containing PDA culture medium and placed in a growth chamber at $20^{\circ} \mathrm{C}$ without light. During incubation, germinated sclerotia were counted until the seventh day. Sclerotia collected from the surface lost their viability after three months, while buried ones remained viable until the seventh month. S. cepivorum sclerotia on the soil surface tend to lose their viability in a shorter period than buried sclerotia.

Keywords: resting structure, longevity, viability

Sclerotium cepivorum Berk. é o agente causal da doença denominada de podridão branca que ataca as aliáceas, sendo mais importante na cultura do alho (Allium sativum) e na cebola $($ A. cepa) $(1,10)$.

A doença é conhecida há muito tempo em algumas áreas produtoras no sul e sudeste do Brasil, causando grandes perdas em lavouras instaladas em locais altamente infestados pelo patógeno e sob condições ambientais favoráveis. O patógeno é favorecido por temperaturas próximas de $20^{\circ} \mathrm{C}$ e sobrevive no solo em pequenas estruturas de coloração negra, com diâmetro variando de 200 a $500 \mu \mathrm{m}$, redondas conhecidas como escleródios (8). No Brasil, a doença pode ocorrer em qualquer local onde o gênero Allium é cultivado, no entanto, a ocorrência é generalizada nas regiões serranas do estado de São Paulo, Rio de Janeiro, Minas Gerais, Santa Catarina e Rio Grande do Sul (10).

As referências sobre a biologia de sobrevivência de escleródios de $S$. cepivorum citam que esses podem sobreviver no solo por vários anos $(4,6,8)$, mas sem detalhes do comportamento ao longo do tempo e seu posicionamento no solo. Mediante a este aspecto, o objetivo desse trabalho foi avaliar a sobrevivência e a viabilidade de sobrevivência de escleródios de $S$. cepivorum localizados na superfície e enterrados a $10 \mathrm{~cm}$ da superfície do solo, em condição de pousio.
O experimento foi conduzido no Instituto Federal Catarinense IFC/Campus Rio do Sul, no município de Rio do Sul - SC, (Latitude: $27^{\circ} 11^{\prime} 07^{\prime}$ S e Longitude: 49³9'39' W, altitude 655 metros) durante o período de doze meses (setembro de 2015 a agosto de 2016). A temperatura média do ar foi de 18,$8 ; 16,1 ; 18,4 ; 20,4 ; 21,8$ e $21,2^{\circ} \mathrm{C}$ e a precipitação de 301; 418;270; 84; 140 e 189 mm, respectivamente, durante os meses de setembro de 2015 a fevereiro de 2016 em que foi constatada a viabilidade dos escleródios no solo.

$\mathrm{O}$ isolado de $S$. cepivorum utilizado no experimento foi obtido da coleção da Epagri - Estação Experimental de Caçador o qual estava preservado em placa de Petri em meio BDA (Batata-dextroseágar) sem antibiótico já apresentando os escleródios. Estes foram multiplicados, primeiramente fazendo uma assepsia com álcool $70 \%$ por 1 minuto, hipoclorito de sódio $1,25 \%$ por 1 minuto e água destilada esterilizada para remoção dos agentes assépticos. Após isso, colocou-se um escleródio por placa de Petri contendo meio de cultura BDA sem antibiótico e incubou-se à $20^{\circ} \mathrm{C}$ em câmara de crescimento do tipo B.O.D. (Demanda Biológica de Oxigênio) no escuro por quatorze dias. Após a multiplicação, foi realizado o teste de avaliação de sobrevivência, onde 100 escleródios foram colocados dentro de 

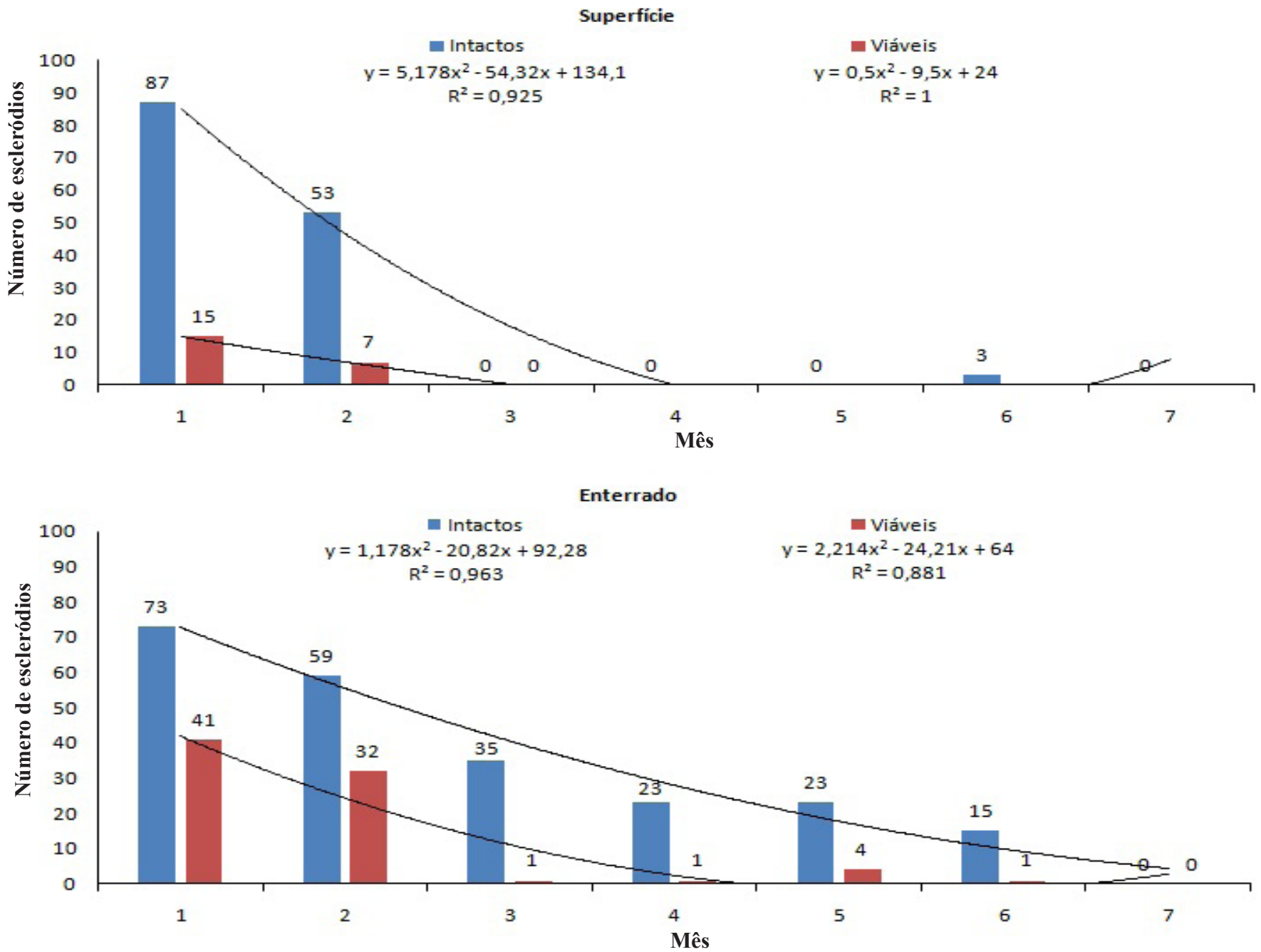

Figura 1. Número de escleródios intactos e viáveis de Sclerotium cepivorum na superfície e enterrados a $10 \mathrm{~cm}$ no solo. IFC/Campus Rio do Sul, $2015 / 2016$.

saquinhos $(10 \mathrm{x} 4 \mathrm{~cm})$ confeccionados de tecido voal e amarrados na extremidade com arame flexível encampado para não haver perdas de escleródios (5).

Os saquinhos com os escleródios foram depositados a campo protegidos lateralmente em uma armação de madeira de $1 \mathrm{~m}^{2}$ com 0,2 $\mathrm{m}$ de profundidade contendo solo, onde 12 saquinhos foram depositados na superfície e 12 enterrados a 10 centímetros de profundidade no solo. O solo utilizado foi um Cambissolo Háplico, com os seguintes atributos químicos: pH em água de 6,0 ; matéria orgânica de $2,8 \%$; teores de $\mathrm{Ca}^{+2}$, $\mathrm{Mg}^{+2}, \mathrm{Al}^{+3}$ e CTC de 4,2; 1,8; 0,0 e 9,54 cmolc. $\mathrm{dm}^{-3}$, respectivamente; saturação por bases de $66,49 \%$, teor de argila de $30 \%$ e teores de P e $\mathrm{K}$ de 14 e $134 \mathrm{mg} . \mathrm{dm}^{-3}$ respectivamente.

Mensalmente foi realizado o teste de sobrevivência dos escleródios, onde foi coletado um saquinho em cada posição no solo. Estes foram lavados em água corrente para remoção do solo aderido e em seguida foram abertos em bancada fazendo a avaliação da rigidez do escleródio através da pressão com auxílio de agulha histológica, caso não se desintegrasse era considerado intacto. Os escleródios intactos foram levados para câmara de fluxo laminar e submetidos à assepsia em álcool $70 \%$ por 1 minuto e hipoclorito de sódio $1,25 \%$ por 3 minutos e água estéril para limpeza e foram depositados no máximo dez escleródios em cada placa de Petri contendo BDA sem antibiótico conforme metodologia utilizada por Rezende \& Zambolim (9). Posteriormente as placas foram colocadas em câmara de crescimento a $20^{\circ} \mathrm{C}$ no escuro. A viabilidade foi avaliada pela contagem da germinação de escleródios diariamente até o décimo quarto dia de incubação. Os percentuais de escleródios intactos e viáveis da superfície e enterrados durante os meses avaliados foram ajustados a uma equação polinomial devido ao maior percentual do coeficiente de determinação $\left(\mathrm{R}^{2}\right)$.

Os escleródios da superfície tiveram um comportamento com decréscimo brusco no número de escleródios viáveis $\left(\mathrm{y}=0,5 \mathrm{x}^{2}\right.$ $9,5 \mathrm{x}+24 ; \mathrm{R}^{2}=1$ ), sendo que no segundo mês foi onde teve a maior redução da viabilidade dos escleródios, sendo acima de $50 \%$ e a partir do terceiro mês eles perderam totalmente sua viabilidade (Figura 1). Como os escleródios da superfície estão sujeitos a ciclos de secagem e molhamento acabam germinando antes em comparação com os enterrados (Figura 1). A relação entre escleródios intactos e viáveis foi alta e após um mês na superfície do solo, $83 \%$ dos escleródios já perderam a viabilidade e no segundo mês a relação foi de $86 \%$ entre os escleródios viáveis e intactos. Os escleródios intactos coletados foi representado por $\mathrm{y}=5,178 \mathrm{x}^{2}-54,32 \mathrm{x}+134,1\left(\mathrm{R}^{2}=0,925\right)$ e verificou-se que do terceiro ao quinto mês nenhum escleródio foi coletado devido já estarem desintegrados, e no sexto mês, três escleródios permaneceram intactos, porém inviáveis (Figura 1). Após o sexto mês nenhum escleródio foi considerado intacto, sendo que os mesmos começaram a se degradar ea partir do oitavo mês não se observou escleródios no 
saquinho.

A viabilidade dos escleródios enterrados $\left(\mathrm{y}=2,214 \mathrm{x}^{2}-24,21 \mathrm{x}+64\right.$; $\left.\mathrm{R}^{2}=0,881\right)$ a $10 \mathrm{~cm}$ de profundidade se estendeu até o sexto mês (Figura 1), no entanto, dois meses após o inicio do experimento foram registrados os maiores valores de escleródios viáveis em relação aos intactos com 97,14\%. A partir do segundo mês, os valores de escleródios viáveis pouco oscilaram (Figura 1), embora o número de escleródios intactos se mostrasse em decréscimo até o sexto mês, representado pela equação $y=1,178 x^{2}-20,82 x+92,28\left(R^{2}=0,963\right)$. Do sétimo ao décimo segundo mês, apesar de haver poucos escleródios no saquinho, ele desintegrava-se no momento que realizava o teste de pressão com auxílio de agulha histológica.

O patógeno $S$. cepivorum não possui esporos funcionais conhecidos e as únicas estruturas para reprodução são os escleródios, que segundo Massola Junior et al. (6) pode persistir no solo por mais de 8 anos. No entanto, Haper (4) verificou que os escleródios de S. cepivorum são deteriorados rapidamente no solo e que sua viabilidade foi reduzida de $100 \%$ para $34 \%$ no primeiro mês e de $52 \%$ após dois meses no solo e que em seis meses, $89 \%$ dos escleródios perderam sua viabilidade em experimento conduzido na Nova Zelândia. Resultado esse semelhante ao encontrado no presente trabalho, em que a partir dos seis meses mais de 90\% dos escleródios perdem a sua viabilidade (Figura 1). Os escleródios enterrados mostraram maior tempo de sobrevivência no solo em relação aos da superfície, possivelmente devido à estabilidade das condições ambientais, já que na superfície do solo estão sujeitos a ciclos de secagem e molhamento e são afetados pela degradação da radiação solar, temperatura e/ou falta de umidade, desta forma germinaram antes dos que foram enterrados (3).

Outro trabalho envolvendo patógeno que forma escleródio foi realizado por Marcuzzo \& Schuller (5) em que avaliando a sobrevivência de escleródios de Sclerotium rolfsii, verificaram que os escleródios enterrados tiveram 15 meses de viabilidade enquanto que os localizados na superfície do solo apenas 9 meses. Brustolin et al. (2) também avaliando a longevidade de escleródios de Sclerotinia sclerotiorum, verificaram que estes perderam sua viabilidade após 12 meses na superfície e de 36 meses quando enterrados no solo
(7). Comportamento semelhante verificado nesse trabalho, já que os escleródios enterrados permanecem úmidos, fazendo que tenham uma dormência maior e menor germinação.

Mediante aos resultados obtidos constatou-se um decréscimo da sobrevivência e viabilidade dos escleródios de $S$. cepivorum produzidos artificialmente, onde os enterrados a $10 \mathrm{~cm}$ permaneceram viáveis por seis meses enquanto que os da superfície não passaram de três meses.

\section{REFERÊNCIAS}

1. Becker, W.F. Doenças do alho: sintomatologia e controle. Florianópolis: Epagri, 2004, 53p. (Boletim técnico 126).

2. Brustolin, R.; Reis, E.M.; Pedron, L. Longevity of Sclerotinia sclerotiorum sclerotia on the soil surface under field conditions. Summa Phytopathologica, Botucatu, v.42, n.2, p.172-174, 2016.

3. Ferraz, L.C.L.; Café Filho, A.C.; Nasser, L.C.B.; Azevedo, J. Effects of soil moisture, organic matter and grass mulching on the carpogenic germination of sclerotinia and infection of bean by Sclerotinia sclerotiorum. Plant Pathology, Edinburgh, v.48, n.7, p.77-82, 1999.

4. Harper, G.E. Aspects of the biology on the sclerotia of Sclerotium cepivorum. 2001, 140 f. Tese (Doutorado) - Lincoln University, Canterbury.

5. Marcuzzo, L.L.; Schuller, A. Sobrevivência e viabilidade de escleródios de Sclerotium rolfsii no solo. Summa Phytopathologica, Botucatu, v.40, n.3, p.281-283, 2014.

6. Massola Junior, N.S.; Jesus Junior, W.C.; Kimati, H. Doenças do alho e da cebola. In: Kimati, H.; Amorim, L.; Rezende, J. A. M.; Bergamim Filho, A.; Camargo, L.E.A. Manual de fitopatologia: doenças das plantas cultivadas. 4 ed. São Paulo: Ceres, 2005. v.2, Cap. 9, p.53-63.

7. Reis, E. M.; Tomazini, S. L. Viabilidade de escleródios de Sclerotinia sclerotiorum em duas profundidades de solo. Summa Phytopathologica, Botucatu, v.31, n.3, p.97-99, 2005.

8. Reis. A.; Oliveira. V.R. Identificação e manejo da podridão-branca do alho e da cebola. Brasília: Embrapa Hortaliças, 2011, 6p. (Comunicado Técnico 91).

9. Rezende, M.L.V.; Zambolim L. Eficiência de métodos utilizados para quantificação da população de escleródios de Sclerotium cepivorum Berk. no solo. Fitopatologia Brasileira, Brasília, v.11, n.10, p.493-500, 1986.

10. Wordell Filho, J.A.; Boff, P. Podridão branca. In: Wordell Filho, J.A.; Rowe, E.; Gonçalves, P.A.; Debarba, J.F.; Boff, P.; Thomazelli, L.F. Manejo Fitossanitário na cultura da cebola. Florianópolis: EPAGRI, p.88-93, 2006. 